\title{
Analysis of the efficacy and safety of a combined gemcitabine, oxaliplatin and pegaspargase regimen for NK/T-cell lymphoma
}

\author{
Jing-hua Wang ${ }^{1,2,3, *}$, Hua Wang ${ }^{1,2,3, *}$, Yan-jun Wang ${ }^{2,3,4, *}$, Zhong-jun Xia ${ }^{1,2,3}$, \\ Hui-qiang Huang ${ }^{2,3,5}$, Wen-qi Jiang ${ }^{2,3,5}$ and Yue Lu',2,3 \\ ${ }^{1}$ Department of Hematological Oncology, Sun Yat-Sen University Cancer Center, Guangzhou, China \\ 2 State Key Laboratory of Oncology in South China, Guangzhou, China \\ ${ }^{3}$ Collaborative Innovation Center for Cancer Medicine, Guangzhou, China \\ 4 Department of Urology, Sun Yat-Sen University Cancer Center, Guangzhou, China \\ ${ }^{5}$ Department of Medical Oncology, Sun Yat-Sen University Cancer Center, Guangzhou, China \\ * These authors have contributed equally to this article
}

Correspondence to: Yue Lu, email: dr_luyue@sina.com

Keywords: extranodal NK/T-cell lymphoma, gemcitabine, oxaliplatin, pegaspargase, adverse effects

Received: November 18,2015 Accepted: March 28, $2016 \quad$ Published: April 07, 2016

\section{ABSTRACT}

Extranodal natural killer/T-cell lymphoma (ENKTL) is an aggressive neoplasm with a poor outcome. Novel L-asparaginase-based treatment regimens, such as GELOX (gemcitabine, oxaliplatin, and L-asparaginase) and P-gemox (gemcitabine, oxaliplatin, and pegaspargase), have shown promising results against stage IE/IIE ENKTL. To define the general applicability of P-gemox, in a retrospective analysis we examined the efficacy and safety of P-gemox in a cohort of 117 patients with newly diagnosed or relapsed/refractory ENKTL. Treatment included 2 to 8 cycles of P-gemox: intravenous gemcitabine $\left(1250 \mathrm{mg} / \mathrm{m}^{2}\right)$ and oxaliplatin $\left(85 \mathrm{mg} / \mathrm{m}^{2}\right)$ and intramuscular pegaspargase ( $2500 \mathrm{IU} / \mathrm{m}^{2}$ ) on day 1 and repeated every 2 weeks, or intravenous gemcitabine $\left(1000 \mathrm{mg} / \mathrm{m}^{2}\right)$ on days 1 and 8 and intravenous oxaliplatin $\left(130 \mathrm{mg} / \mathrm{m}^{2}\right)$ and intramuscular pegaspargase $\left(2500 \mathrm{IU} / \mathrm{m}^{2}\right)$ on day 1 and repeated every 3 weeks. Upon completion of treatment, the overall response rate was $\mathbf{8 8 . 8 \%}$, and responses were similar for newly diagnosed and relapsed/refractory patients. After a median follow-up of 17 months, the 3-year overall and progression-free survival rates were $\mathbf{7 2 . 7 \%}$ and $\mathbf{5 7 . 8 \%}$, respectively. Multivariate analysis showed that CR after treatment was the most significant factor affecting survival. P-gemox thus appears to be an effective and well-tolerated treatment for patients with ENKTL.

\section{INTRODUCTION}

Although rare in the world, extranodal natural killer (NK)/T-cell lymphoma (ENKTL) is diagnosed comparatively frequently in Asia and Latin America and accounts for $5 \%$ to $10 \%$ of all malignant lymphomas in China [1, 2]. ENKTL most often originates in the nasal and upper aerodigestive tract, but can also arise in the skin, soft tissue, gastrointestinal tract, and testis [1, 3, 4]. For patients with localized ENKTL, radiation therapy (RT) alone yields overall response rates (ORRs) of $77 \%$ to $100 \%$, with complete response $(\mathrm{CR})$ rates of $52 \%$ to $100 \%$
[5-8]. On the other hand, the disease recurs in $25 \%$ to $40 \%$ of those patients [5], suggesting chemotherapy is needed to reduce the incidence of systemic failure. Patients with advanced-stage or relapsed/refractory ENKTL follow an extremely aggressive clinical course, during which chemotherapy is a mainstay treatment [9]. However, outcomes are most often poor with conventional CHOPbased chemotherapy regimens, as $>60 \%$ of patients suffer resistant disease [10-13]. The high incidence of resistance is likely related to the high concentrations of P-glycoprotein within ENKTL cells, which results in the tumor cells exhibiting multidrug resistance (MDR) [14, 
Table 1: Characteristics of ENKTL patients treated using the P-gemox regimen

\begin{tabular}{|c|c|c|c|}
\hline Characteristic & \begin{tabular}{|l|}
$\begin{array}{l}\text { Newly } \\
\text { diagnosed }\end{array}$ \\
\end{tabular} & \begin{tabular}{|l|} 
Relapsed/ \\
refractory
\end{tabular} & Overall (\%) \\
\hline $\begin{array}{l}\text { No. } \\
\text { Age, years } \\
<55 \\
\geq 55 \\
\text { Gender } \\
\text { Male } \\
\text { Female } \\
\text { Primary site } \\
\text { UENKTL } \\
\text { EUENKTL } \\
\text { B symptoms } \\
\text { Present } \\
\text { Absent } \\
\text { sLDH } \\
\text { Normal } \\
\text { Increased } \\
\text { ECOG PS } \\
0 \\
1 \\
2 \\
\text { Ann Arbor stage } \\
\text { I/II } \\
\text { III/IV } \\
\text { IPI score } \\
\leq 1 \\
>1\end{array}$ & $\begin{array}{l}96 \\
73 \\
23 \\
67 \\
29 \\
81 \\
15 \\
50 \\
46 \\
66 \\
30 \\
72 \\
19 \\
5 \\
78 \\
18 \\
70 \\
26\end{array}$ & \begin{tabular}{|l}
21 \\
19 \\
2 \\
13 \\
8 \\
18 \\
3 \\
10 \\
11 \\
15 \\
6 \\
18 \\
3 \\
0 \\
12 \\
9 \\
12 \\
9
\end{tabular} & $\begin{array}{l}117 \\
92(78.6) \\
25(21.4) \\
80(68.4) \\
37(31.6) \\
\\
99(84.6) \\
18(15.4) \\
60(51.3) \\
57(48.7) \\
81(69.2) \\
36(30.8) \\
90(76.9) \\
22(18.8) \\
5(4.3) \\
90(76.9) \\
27(23.1) \\
82(70.1) \\
35(29.9)\end{array}$ \\
\hline
\end{tabular}

Abbreviations: P-gemox, gemcitabine,oxaliplatin and pegaspargase; UENKTL, upper aerodigestive tract NK/T-cell lymphoma; EUENKTL, upper aerodigestive tract NK/T-cell lymphoma; B symptoms include unexplained fever with temperature above $38 \mathrm{C}$, night sweats or weight loss more than 10\% within 6 months; sLDH, serum lactate dehydrogenase; ECOG PS, Eastern Cooperative Oncology Group performance status; IPI, International Prognostic Index.

$15]$.

Several novel chemotherapy regimens based around L-asparaginase have recently emerged. For example combined dexamethasone, methotrexate, ifosfamide, L-asparaginase, and etoposide (SMILE) or combined asparaginase, methotrexate, and dexamethasone (AspaMetDex) achieve a complete response (CR) in $40 \%$ to $60 \%$ of cases [16-18]. The anticancer effect of $\mathrm{L}$-asparaginase is not affected by MDR due to its unique mechanism. L-Asparaginase digests serum asparagine, and since ENKTL cells cannot synthesize asparagine themselves, tumor cell proliferation is suppressed [19]. PEG-asparaginase (pegaspargase), a form of Escherichia coli L-asparaginase covalently linked to polyethylene glycol, was rationally synthesized to decrease the immunogenicity of the enzyme and prolong its half-life. PEG-asparaginase has been granted approval as a first-line drug for the treatment of acute lymphoblastic leukemia [20] and also showed good therapeutic effect against ENKTL in recent clinical trials [21-23]. In a prospective study at our center, GELOX (gemcitabine, oxaliplatin, and L-asparaginase) and P-gemox (gemcitabine, oxaliplatin, and pegaspargase) regimens were tested in patients with stage IE/IIE ENKTL, and the results were promising [22]. To define the general applicability of P-gemox, in the present study, we systematically evaluated the potential efficacy and safety of this regimen in a large cohort of patients with newly diagnosed and relapsed/refractory ENKTL.

\section{RESULTS}

\section{Patient characteristics}

The patient characteristics are listed in Table 1. Our cohort included 96 newly diagnosed and 21 relapsed/ refractory patients. The median age was 43 years (range, 13 years to 77 years), with 92 patients $(78.6 \%)$ less than 55 years old. The male:female ratio was $2.2: 1$. The majority of patients $(84.6 \%)$ were UENKTL cases - i.e., their ENKTLs orginated in the upper aerodigestive tract - and they showed good ECOG PS, IPI, and early-stage disease based on the Ann Arbor staging system. Eight patients with hepatitis B surface antigen (HBsAg)-positive, and were treated with antiviral medications. For relapsed/refractory patients, previous treatments included anthracyclinecontaining regimens (cyclophosphamide, doxorubicin, vincristine, and prednisolone [CHOP] or CHOP-like 
Table 2: Treatment outcomes to P-gemox chemotherapy

\begin{tabular}{|l|l|l|l|l|l|l|l|l|l|}
\hline Disease status & $\boldsymbol{n}$ & $\begin{array}{l}\text { Interim } \\
\text { CR(\%) }\end{array}$ & $\boldsymbol{p}$ & $\begin{array}{l}\text { Interim } \\
\text { ORR(\%) }\end{array}$ & $\boldsymbol{p}$ & $\begin{array}{l}\text { Completion } \\
\text { CR(\%) }\end{array}$ & $\boldsymbol{p}$ & $\begin{array}{l}\text { Completion } \\
\text { ORR(\%) }\end{array}$ & $\boldsymbol{p}$ \\
\hline Newly diagnosed & 96 & $32(33.3)$ & 0.800 & $80(83.3)$ & 0.125 & $58(60.4)$ & 0.625 & $87(90.6)$ & 0.247 \\
\hline Relapsed/refractory & 21 & $8(38.1)$ & & $14(66.6)$ & & $11(52.4)$ & & $17(80.9)$ & \\
\hline All patients & 117 & $40(34.2)$ & & $94(80.3)$ & & $69(58.9)$ & & $104(88.8)$ & \\
\hline
\end{tabular}

Abbreviations: P-gemox, gemcitabine, oxaliplatin and Pegaspargase; CR, complete response; ORR, overall response rate.

regimens) alone $(N=17)$ or followed by radiotherapy $(N$ $=2$ ), the $2 / 3 \mathrm{DeVIC}$ regimen (dexamethasone, etoposide, ifosfamide, and carboplatin) with radiotherapy $(N=1)$, and radiotherapy alone $(N=1)$.

\section{Treatment and response}

The median number of P-gemox cycles among the 117 patients was 4 (range, 2-8 cycles). A total of 65 patients received radiotherapy, and the number of newly diagnosed patients who received radiotherapy was comparable to the number in relapsed/refractory patients. Other patients did not receive radiotherapy because of the high cost of treatment, disease progression, previous radiotherapy, or other personal reasons. Eight patients underwent hematopoietic stem cell transplantation (HSCT) after achieving interim CR or PR.

For the whole cohort, interim analysis showed a CR rate of $34.2 \%$ and an ORR rate of $80.3 \%$. By treatment completion, the $\mathrm{CR}$ rate had improved to $58.9 \%$ and the ORR rate to $88.8 \%$, whereas two patients remained $\mathrm{SD}$, and seven developed PD. Treatment outcomes

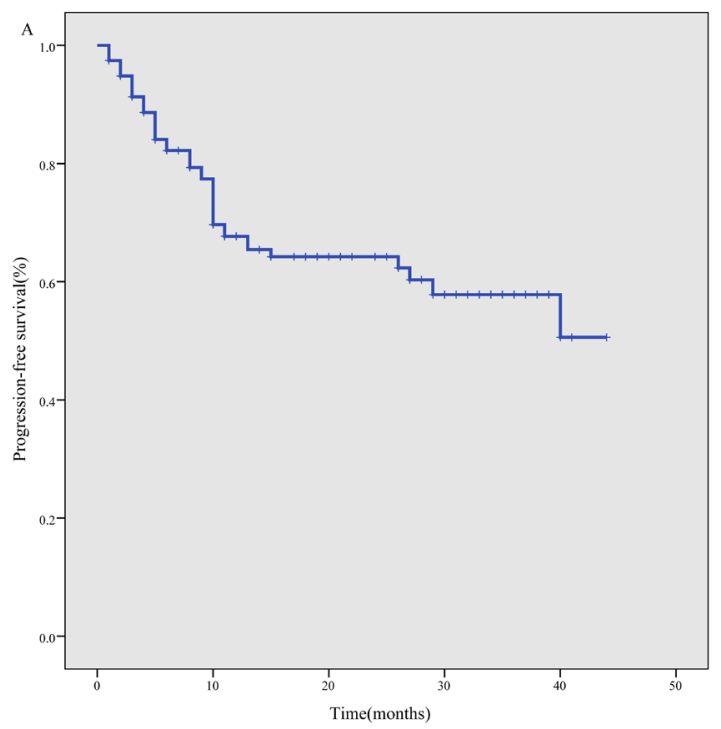

are summarized in Table 2; note that the interim and completion response rates were comparable between newly diagnosed and relapsed/refractory patients.

\section{Survival}

The median follow-up time was 17 months, with a range of 1 month to 51 months. The 3 -year PFS was $57.8 \%$ (95\% CI, 47.2\%-68.4\%) for the whole cohort (Figure 1A), 65.4\% (95\% CI, 53.4\%-77.4\%) for newly diagnosed patients and $23.7 \%$ (95\% CI, 4.6\%-42.8\%) for relapsed/refractory patients. The 3 -year OS was $72.7 \%$ (95\% CI, 63.4\%-81.9\%) for the whole cohort (Figure 1B), $75.6 \%$ (95\% CI, 66.0\%-85.3\%) for newly diagnosed patients, and $57.7 \%$ (95\% CI, 30.0\%-85.4\%) for relapsed/ refractory patients.

In a subgroup analysis, newly diagnosed patients showed better PFS than relapsed/refractory patients $(P<$ $0.001)$, but there was no significant difference in OS $(P=$ 0.358). Similarly, PFS among stage I-II patients was better than among stage III-IV patients $(P<0.001)$, but again there was no significant difference in OS $(P=0.166)$. Our

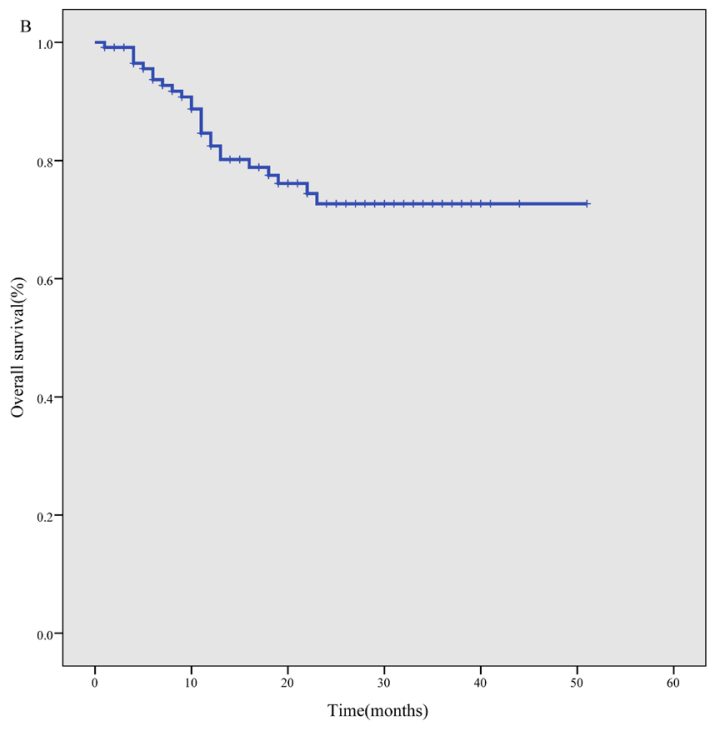

Figure 1: Survival curves for 117 ENKTL patients treated using the P-gemox regimen. A. progression- free survival, B. overall survival. 
Table 3: Univariate and multivariate analysis of prognostic factors for survivals after P-gemox therapy

\begin{tabular}{|c|c|c|c|c|c|c|c|c|}
\hline \multirow[b]{3}{*}{ Clinical factors } & \multicolumn{4}{|c|}{ Progression- free survival } & \multicolumn{4}{|c|}{ Overall survival } \\
\hline & \multicolumn{2}{|c|}{ Univariate } & \multicolumn{2}{|c|}{ Multivariate } & \multicolumn{2}{|c|}{ Univariate } & \multicolumn{2}{|c|}{ Multivariate } \\
\hline & $p$ & HR (\%95 CI) & $p$ & $\begin{array}{l}\text { HR } \\
\text { CI })\end{array}$ & $p$ & HR (\%95 CI) & $p$ & HR (\%95 CI) \\
\hline \multicolumn{9}{|l|}{ Whole cohort } \\
\hline $\begin{array}{l}\text { Newly diagnosed or } \\
\text { relapsed/refractory }\end{array}$ & 0.000 & $\begin{array}{l}3.362(1.782- \\
6.341) \\
\end{array}$ & 0.004 & \begin{tabular}{|l}
$2.642(1.375-$ \\
$5.079)$
\end{tabular} & 0.361 & \begin{tabular}{|l}
$0.654(0.261-$ \\
$1.638)$
\end{tabular} & - & - \\
\hline Age & 0.564 & $\begin{array}{l}0.805(0.385- \\
1.685) \\
\end{array}$ & - & - & 0.261 & $\begin{array}{l}0.609(0.254- \\
1.458) \\
\end{array}$ & - & - \\
\hline EUENKTL & 0.047 & $\begin{array}{l}1.988(0.997- \\
3.962)\end{array}$ & - & - & 0.030 & $\begin{array}{l}2.457(1.060- \\
5.696)\end{array}$ & - & - \\
\hline $\mathrm{LDH}$ & 0.312 & $\begin{array}{l}1.384(0.735- \\
2.603) \\
\end{array}$ & - & - & 0.231 & \begin{tabular}{|l|}
$1.623(0.729-$ \\
$3.614)$ \\
\end{tabular} & - & - \\
\hline Stage & 0.000 & $\begin{array}{l}3.082(1.659- \\
5.726) \\
\end{array}$ & - & - & 0.169 & $\begin{array}{l}1.790(0.772- \\
4.150)\end{array}$ & - & - \\
\hline IPI & 0.000 & $\begin{array}{l}3.679(1.997- \\
6.780) \\
\end{array}$ & - & - & 0.002 & $\begin{array}{l}3.163(1.441- \\
6.940) \\
\end{array}$ & 0.047 & \begin{tabular}{|l}
$2.322(1.013-$ \\
$5.324)$ \\
\end{tabular} \\
\hline CR after treatment & 0.000 & $\begin{array}{l}2.970(1.597- \\
5.520)\end{array}$ & 0.013 & $\begin{array}{l}2.265(1.191- \\
4.309)\end{array}$ & 0.002 & $\begin{array}{l}3.376(1.489- \\
7.654)\end{array}$ & 0.027 & $\begin{array}{l}2.619(1.117- \\
6.139)\end{array}$ \\
\hline \multicolumn{9}{|l|}{ Newly diagnosed } \\
\hline EUENKTL & 0.032 & $\begin{array}{l}2.410(1.052- \\
5.517)\end{array}$ & - & - & 0.009 & $\begin{array}{l}3.222(1.265- \\
8.208)\end{array}$ & - & - \\
\hline Age & 0.493 & $\begin{array}{l}0.740(0.313- \\
1.753) \\
\end{array}$ & - & - & 0.569 & $\begin{array}{l}0.744(0.268- \\
2.068) \\
\end{array}$ & - & - \\
\hline B symptoms & 0.032 & $\begin{array}{l}2.400(1.050- \\
5.484)\end{array}$ & - & - & 0.291 & $\begin{array}{l}1.645(0.647- \\
4.182) \\
\end{array}$ & - & - \\
\hline $\mathrm{LDH}$ & 0.074 & $\begin{array}{l}1.977(0.922- \\
4.239)\end{array}$ & - & - & 0.097 & \begin{tabular}{|l}
$2.110(0.857-$ \\
$5.195)$
\end{tabular} & - & - \\
\hline Stage & 0.004 & $\begin{array}{l}3.025(1.377- \\
6.643)\end{array}$ & - & - & 0.028 & $\begin{array}{l}2.725(1.072- \\
6.927)\end{array}$ & - & - \\
\hline IPI & 0.000 & $\begin{array}{l}4.791(2.221- \\
10.337) \\
\end{array}$ & 0.005 & \begin{tabular}{|l}
$4.421(1.552-$ \\
$12.593)$ \\
\end{tabular} & 0.000 & \begin{tabular}{|l}
$4.913(1.967-$ \\
$12.268)$ \\
\end{tabular} & 0.003 & \begin{tabular}{|l} 
6.450(1.872- \\
$22.228)$ \\
\end{tabular} \\
\hline $\mathrm{CR}$ after treatment & 0.001 & $\begin{array}{l}3.502(1.596- \\
7.683)\end{array}$ & 0.021 & $\begin{array}{l}2.808(1.170- \\
6.740)\end{array}$ & 0.000 & \begin{tabular}{|l}
$5.546(1.994-$ \\
$15.431)$ \\
\end{tabular} & 0.001 & \begin{tabular}{|l}
$4.238(1.387-$ \\
$12.952)$ \\
\end{tabular} \\
\hline
\end{tabular}

Abbreviations: EUENKTL, extra-upper aerodigestive tract NK/T-cell lymphoma; IPI, International Prognostic Index; B symptoms include unexplained fever with temperature above $38^{\circ} \mathrm{C}$, night sweats or weight loss more than $10 \%$ within 6 months; HR, hazard ratio; CI, confidence interval.

study also showed that both the PFS $(P<0.001)$ and OS $(P=0.002)$ rates were significantly better among patients who attained a CR by the end of treatment than among those without a CR (Figures 2A to 2B). In addition, a lower IPI score predicted a significantly better PFS $(P<$ $0.001)$ and $\mathrm{OS}(P=0.002)$ (Figures $2 \mathrm{C}$ to $2 \mathrm{D})$. Finally, we found that newly diagnosed patients who received combined radiotherapy and chemotherapy showed better PFS $(P=0.028)$ and OS $(P=0.012)$ than those who received chemotherapy alone (Figure $2 \mathrm{E}-2 \mathrm{~F}$ ).

\section{Prognostic factors for PFS and OS}

Univariate analysis of the whole cohort revealed that the significant factors affecting PFS included newly diagnosed or relapsed/refractory at entry $(P<0.001)$, EUENKTL (primary tumors at any site excluding nasal disease) $(P=0.047)$, stage $(P<0.001)$, IPI $(P<0.001)$, and CR status $(P<0.001)$. For newly diagnosed patients, EUENKTL $(P=0.032)$, B symptoms $(P=0.032)$, stage $(P=0.004)$, IPI $(P<0.001)$, and CR status $(P=0.001)$ were significant factors. Multivariate analysis showed that newly diagnosed or relapsed/refractory at entry $(P$ $=0.004)$ and $\mathrm{CR}$ status $(P=0.013)$ remained significant independent factors for the whole cohort, while IPI $(P=$ $0.005)$ and $C R$ status $(P=0.021)$ significantly affected PFS for newly diagnosed patients (Table 3 ).

Univariate analysis of the whole cohort revealed that the significant factors affecting OS included EUENKTL $(P=0.030)$, IPI $(P=0.002)$ and CR status $(P=0.002)$. For newly diagnosed patients, EUENKTL $(P=0.009)$, 

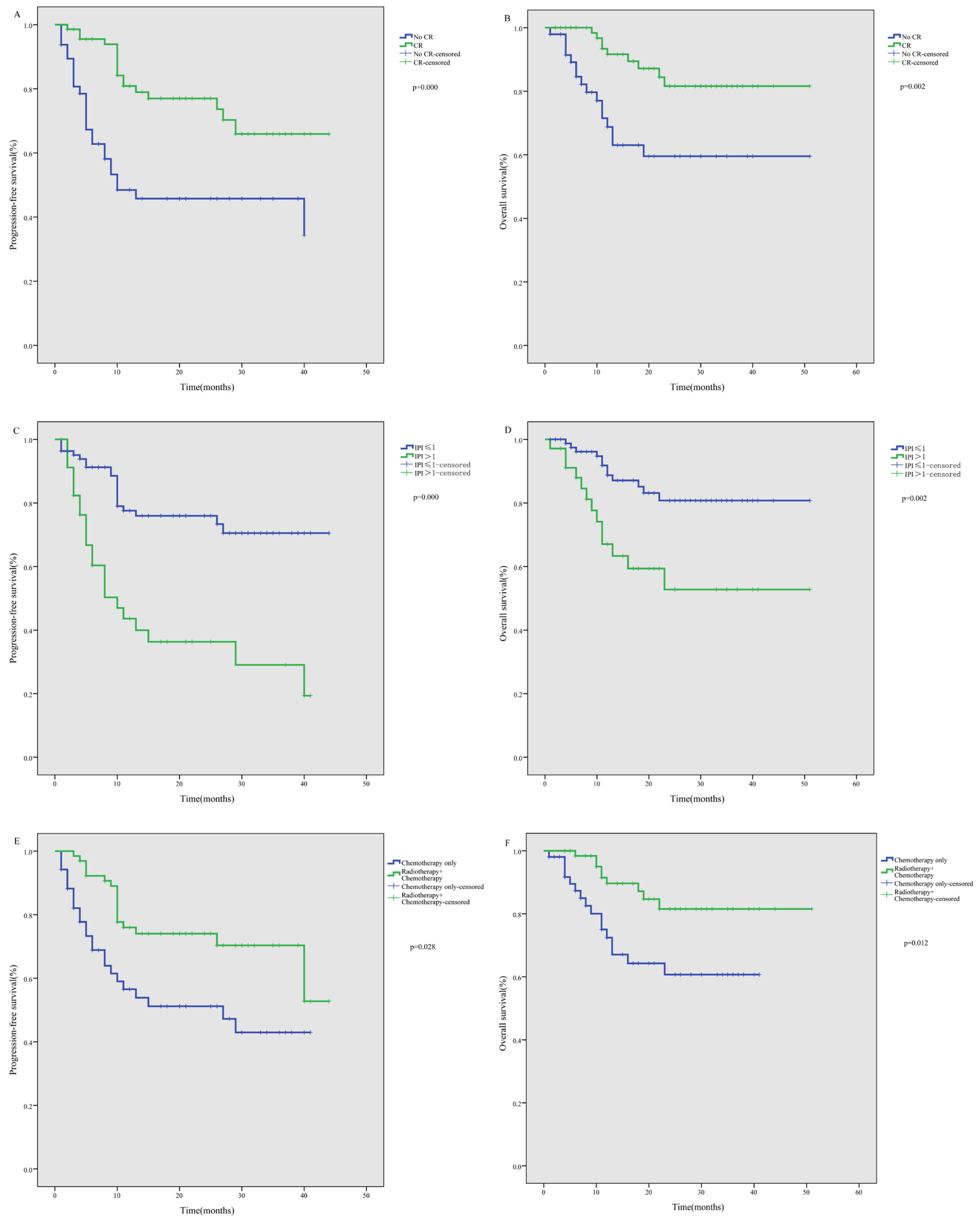

Figure 2: Subgroup analysis of survival among ENKTL patients treated using the P-gemox regimen. A. Significant impact of treatment response on progression-free survival (PFS). B. Significant impact of treatment response on overall survival (OS). C. Significant impact of IPI on PFS. D. Significant impact of IPI on OS. E. Significant impact of radiotherapy on PFS among newly diagnosed patients. F. Significant impact of radiotherapy on OS among newly diagnosed patients. 
Table 4: Adverse effects of P-gemox chemotherapy

\begin{tabular}{|c|c|c|c|c|}
\hline Adverse effects & $\begin{array}{c}\text { Newly } \\
\text { diagnosed }\end{array}$ & $\begin{array}{l}\text { Relapsed/ } \\
\text { refractory }\end{array}$ & All cases( $(\%)$ & $p$ \\
\hline \multicolumn{5}{|l|}{ Leukopenia } \\
\hline Grade $1 / 2$ & 55 & 11 & $66(56)$ & \\
\hline Grade 3/4 & 18 & 8 & $26(22)$ & 0.08 \\
\hline \multicolumn{5}{|l|}{ Neutropenia } \\
\hline Grade $1 / 2$ & 45 & 9 & $54(46)$ & \\
\hline Grade $3 / 4$ & 28 & 7 & $35(30)$ & 0.79 \\
\hline \multicolumn{5}{|l|}{ Anemia } \\
\hline Grade $1 / 2$ & 68 & 19 & $87(74)$ & \\
\hline Grade $3 / 4$ & 18 & 2 & $20(17)$ & 0.52 \\
\hline \multicolumn{5}{|l|}{ Thrombocytopenia } \\
\hline Grade $1 / 2$ & 20 & 5 & $25(21)$ & \\
\hline Grade 3/4 & 17 & 4 & $21(18)$ & 1.00 \\
\hline Gastrointestinal disorders & 34 & 6 & $40(34)$ & 0.62 \\
\hline \multicolumn{5}{|l|}{ Increased transaminases } \\
\hline Grade $1 / 2$ & 72 & 17 & $89(76)$ & \\
\hline Grade $3 / 4$ & 10 & 0 & $10(8.5)$ & 0.21 \\
\hline Hyperbilirubinaemia & 46 & 2 & $48(41)$ & 0.00 \\
\hline Coagulopathy & 47 & 7 & $54(46)$ & 0.23 \\
\hline Hypofibrinogenemia & 50 & 5 & $55(47)$ & 0.03 \\
\hline Increase in BUN & 29 & 2 & $30(26)$ & 0.06 \\
\hline Hypertriglyceridemia & 61 & 14 & $75(64)$ & 1.00 \\
\hline Hyperglycemia & 23 & 5 & $28(24)$ & 1.00 \\
\hline Hypoglycemia & 24 & 5 & $29(25)$ & 1.00 \\
\hline Hypoalbuminemia & 50 & 5 & $55(47)$ & 1.00 \\
\hline deep-vein thrombosis & 1 & 1 & $2(1.7)$ & 0.33 \\
\hline allergic reactions & 1 & 0 & $1(0.8)$ & 1.00 \\
\hline pancreatitis & 2 & 0 & $2(1.7)$ & 1.00 \\
\hline
\end{tabular}

Abbreviations: P-gemox, gemcitabine, oxaliplatin and Pegaspargase.

stage $(P=0.028)$, IPI $(P<0.001)$, and CR status $(P<$ $0.001)$ were significant predictors. Multivariate analysis showed that IPI $(P=0.047$ and 0.003$)$ and CR status $(P=$ 0.027 and 0.001$)$ remained significant independent factors for the whole cohort and for newly diagnosed patients (Table 3).

\section{Adverse effects}

Treatment-related adverse effects are shown in Table 4. The most common adverse effect of the P-gemox regimen was hematological toxicity. However, nonhematologic toxicities were also frequent, though most reported cases were mild. Gastrointestinal disorders, including nausea, emesis, and diarrhea, were observed in 40 patients. Mild coagulation abnormalities, which were reflected by prolongation of the activated partial thromboplastin time (APTT), were observed in 54 patients. Two patients developed left upper limb deep-vein thrombosis, but revascularization was achieved following treatment with anticoagulant. One patient developed an allergic reaction, and two patients developed pancreatitis. Because of adverse effects, the doses administered to 11 patients were reduced or chemotherapy was delayed. A 72-year-old man died from suffocation during the second cycle of chemotherapy. No difference in the incidence of adverse effects was observed between newly 
Table 5: Study comparison of pegaspargase- or L-asparaginase-based regimens in the treatment of ENKTL

\begin{tabular}{|c|c|c|c|c|c|c|c|c|c|}
\hline \multirow[b]{2}{*}{ Disease status } & \multirow[b]{2}{*}{ No. } & \multirow[b]{2}{*}{ Treatment } & \multicolumn{2}{|c|}{ Response } & \multicolumn{2}{|l|}{ Survival } & \multicolumn{2}{|c|}{ Adverse effects } & \multirow[b]{2}{*}{ Reference } \\
\hline & & & ORR & CR & OS & PFS & $\begin{array}{lr}\text { Grade } \quad 3 / 4 \\
\text { neutropenia }\end{array}$ & \begin{tabular}{|lr} 
Grade $3 / 4$ \\
hepatotoxicity
\end{tabular} & \\
\hline $\begin{array}{l}\text { Newly diagnosed, } \\
\text { relapsed/refractory, } \\
\text { any stage }\end{array}$ & 117 & $\begin{array}{l}\text { P-gemox } \pm \\
\text { sandwiched } \\
\text { RT (56 Gy) }\end{array}$ & $88 \%$ & $59 \%$ & $3 y: 73 \%$ & $3 \mathrm{y}: 58 \%$ & $30 \%$ & $8.5 \%$ & this study \\
\hline $\begin{array}{l}\text { Newly diagnosed, } \\
\text { relapsed/refractory, } \\
\text { any stage }\end{array}$ & 87 & $\begin{array}{l}\text { SMILE } \pm \\
\text { sandwiched } \\
\text { RT (50 Gy) }\end{array}$ & $81 \%$ & $66 \%$ & 5 y: $50 \%$ & $\begin{array}{l}4 \text { y DFS: } \\
64 \%\end{array}$ & $67 \%$ & $7 \%$ & 17 \\
\hline $\begin{array}{l}\text { Newly diagnosed, } \\
\text { stage IV, or } \\
\text { relapsed/refractory }\end{array}$ & 38 & SMILE & $79 \%$ & $45 \%$ & $1 \mathrm{y}: 55 \%$ & $1 \mathrm{y}: 53 \%$ & $100 \%$ & $32 \%$ & 16 \\
\hline Relapsed/refractory & 19 & AspaMetDex & $78 \%$ & $61 \%$ & $2 \mathrm{y}: 40 \%$ & $2 \mathrm{y}: 40 \%$ & $42 \%$ & $16 \%$ & 18 \\
\hline $\begin{array}{l}\text { Newly diagnosed, } \\
\text { stage I/II nasal }\end{array}$ & 27 & $\begin{array}{l}\text { GELOX } \\
\pm \text { sandwiched } \\
\text { RT (56 Gy) }\end{array}$ & $96 \%$ & $74 \%$ & 2 y: $86 \%$ & 2 y: $86 \%$ & $33.3 \%$ & $3.7 \%$ & 22 \\
\hline
\end{tabular}

Abbreviations: No., number; ORR, overall response rate; CR, complete remission; OS, overall survival; PFS, progressionfree survival; DFS, disease-free survival; RT, radiotherapy; y, year; P-gemox, gemcitabine,oxaliplatin and pegaspargase; SMILE, methotrexate, ifosfamide, dexamethasone, etoposide, and L-asparaginase; AspaMetDex, L-asparaginase, methotrexate, and dexamethasone; GELOX, gemcitabine, oxaliplatin, and L-asparaginase.

diagnosed and relapsed/refractory patients, except for hyperbilirubinaemia $(P<0.001)$ and hypofibrinogenemia $(P=0.03)$

\section{DISCUSSION}

ENKTL is a highly invasive tumor with a short doubling time and poor prognosis. How best to treat ENKTL has been a troublesome issue because the disease frequently shows resistance to anthracyclinebased chemotherapy due to MDR, and local radiation therapy often fails to prevent systemic disease relapse or progression [5]. With this study, we aimed to determine a treatment strategy for ENKTL that is more effective and better tolerated than previously reported treatments.

Gemcitabine is a nucleoside analogue that has shown promising results in non-Hodgkin lymphoma [24-26]. A retrospective study of gemcitabine alone or as part of a chemotherapy regimen for relapsed/refractory ENKTL recently reported that $40 \%$ of patients showed an objective response [27]. Oxaliplatin is another drug effective against non-Hodgkin lymphoma, with a singledrug objective response rate of $27 \%$ to $40 \%$ [28]. When gemcitabine and oxaliplatin were used in combination, a synergistic effect was observed in vitro and in clinical studies with lymphoma [29, 30]. L-asparaginase is an antitumor drug with a unique mechanism of action, and several L-asparaginase-based regimens have exhibited promising results in patients with newly diagnosed or relapsed/refractory ENKTL. Pegaspargase, the apegylated form of L-asparaginase, is associated with a lower incidence of induction of anti-asparaginase antibodies and exhibits more prolonged asparaginase activity than native asparaginase [31]. Results from several case reports and clinical studies with small sample sizes suggest pegaspargase may be effective in selected patients $[21,22$, $32,33]$. We selected pegaspargase for its ability to induce more prolonged continuous asparagine depletion as well as for its ease of administration, as only a single treatment every 2 to 3 weeks is required. We then developed the P-gemox regimen, which includes a combination of gemcitabine, oxaliplatin, and pegaspargase, all of which are non-anthracycline drugs that exhibited significant activity and non-overlapping toxicity in previous studies, and are unaffected by MDR.

In the present study, the ORR of P-gemox for the whole cohort was $80.3 \%$ at interim and $88.8 \%$ on completion, and $53(45.3 \%)$ patients were alive in continuous $\mathrm{CR}$ at the end of follow-up. This highlights the favorable long-term outcome of this regimen and demonstrates that $\mathrm{P}$-gemox is an effective regimen that induces a swift response. Moreover, the response rates were similar for newly diagnosed patients receiving P-gemox as upfront therapy and relapsed/refractory patients receiving it as salvage.

It is noteworthy that whereas the survival analysis indicated that newly diagnosed patients showed better PFS than relapsed/refractory patients, there was no significant difference in OS. We think there are two reasons for this. First, the number of relapsed/refractory patients included in the present study is relatively small, so the conclusion remains to be confirmed in larger, multiple-center trials. Second, when disease progression began again in relapsed/ refractory patients after treatment with the P-gemox regimen, they were treated with HSCT or new drugs such as Lenalidomide, which enabled most to achieve remission and survive. Nonetheless, we suggest newly diagnosed patients will show better OS than relapsed/refractory 
patients if follow-up is extended. In addition, among newly diagnosed patients, those who received combined radiotherapy and chemotherapy showed better PFS and OS than those who received chemotherapy only. This indicates that radiotherapy serves an important purpose in the treatment of newly diagnosed ENKTL.

For comparison of our results with those of earlier studies of ENKTL, Table 5 summarizes the latest published results obtained with L-asparaginase-based regimens. These regimens all yielded promising results in patients with newly diagnosed or relapsed/refractory ENKTL. Table 5 shows that the treatment response and survival outcomes achieved with the P-gemox regimen are superior or similar to those obtained with other regimens, which is indicative of the excellent antitumor effect of the P-gemox regimen.

Multivariate analysis of the whole cohort showed that relapsed/refractory at entry, EUENKTL, stage III-IV, IPI $>1$, and no CR were independent factors associated with relapse or poor survival in ENKTL. These factors differed from those reported by Lee et al., which included B symptoms, stage, LDH level, and lymph node involvement as independent prognostic factors [3]. This difference may be due to the smaller number of participants in our study or the high efficacy of pegaspargase. Investigations using a larger patient cohort will be needed to identify the appropriate prognostic factors for ENKTL in the era of non-anthracycline-based chemotherapy.

Among adverse events, grade $3 / 4$ toxicities were mainly hematological. Dose reduction and timely application of G-CSF were essential when patients experienced severe cytopenias during or after chemotherapy. Other support treatments, such as platelet transfusion and infection prevention, were also necessary. Commonly reported side effects of pegaspargase therapy include gastrointestinal disorders, liver dysfunction, coagulopathy, hypertriglyceridemia, hyperglycemia, and hypoalbuminemia [34]. In our study, grade 1 and 2 toxicities were frequently relating to these side effects and could be well controlled by symptomatic treatments. Venous thrombosis is another known adverse event associated with asparaginase. During our study period, two patients developed left upper limb deep venous thrombosis, but revascularization was achieved following anticoagulant treatment. Thus, patients should be monitored closely for thrombosis during follow-up and in subsequent trials. One allergic reaction and two pancreatitis cases were also observed in this study, and one treatment-related death was attributed to suffocation. The hematologic toxicities and liver dysfunction seen in our study were considerably milder than those reported with the SMILE and AspaMetDex regimens (Table 5). In sum, the P-gemox regimen presented acceptable toxicity profiles.

In conclusion, this study demonstrated that P-gemox is a more effective and well-tolerated treatment for patients with newly diagnosed, relapsed, or refractory ENKTL.

\section{MATERIALS AND METHODS}

\section{Patients}

From October 2010 to January 2015, a total of 117 patients with newly-diagnosed or relapsed/refractory ENKTL who were treated with P-gemox at Sun Yat-sen University Cancer Center were identified and included in this retrospective analysis. Clinical information was obtained through a review of medical records. The inclusion criteria for this retrospective study were (1) a pathologically confirmed diagnosis of ENKTL based on the WHO classification of Tumors of Hematopoietic and Lymphoid Tissues; (2) NK/T-cell type proven by immunohistochemistry, Epstein-Barr virus (EBV) in situ hybridization or flow cytometry; (3) adequate hematologic function (hemoglobin $>90 \mathrm{~g} / \mathrm{L}$, absolute neutrophil count $>1.5 \times 10^{9} / \mathrm{L}$, and platelet count $\left.>100 \times 10^{9} / \mathrm{L}\right)$, renal function (serum creatinine $\leq 1.5 \mathrm{mg} / \mathrm{dL}$ and creatinine clearance $\geq 50 \mathrm{~mL} / \mathrm{min}$ ), and hepatic function (total bilirubin $\leq 2$ times the upper limit of normal and aspartate and alanine transaminase levels $\leq 3$ times the upper limit of normal); (4) no previous or concomitant malignancies; and (5) a complete set of clinical information and followup data. Patients with aggressive NK-cell leukemia, negative EBV in situ hybridization, CNS involvement, pregnancy, or lactation were excluded. Based on the primary tumor site, the cancers were classified as upper aerodigestive tract NK/T-cell lymphoma (UENKTL: primary tumors confined to the nasal cavity, nasopharynx, paranasal sinuses, tonsils, hypopharynx, and larynx) or extra-UENKTL (EUENKTL: primary tumors at all sites excluding nasal disease) [3]. Primary tumors within the nasal cavity with secondary spread to other organs were regarded as UENKTL. This study design was approved by the SunYat-sen University Cancer Center Research Ethics Board. All of the patients agreed that their medical information could be used for medical research, and signed an informed consent during their first visit.

Patients were staged on the basis of Ann Arbor staging system; International Prognostic Index (IPI) scores, which were calculated on the basis of demographic characteristics; a physical examination; Eastern Cooperative Oncology Group performance status (ECOG PS); systemic B symptoms (unexplained fever with temperature above $38^{\circ} \mathrm{C}$, night sweats or weight loss exceeding 10\% within 6 months); complete blood count; serum biochemistry with lactate dehydrogenase (LDH); computed tomography (CT) scans of the chest, abdomen, and pelvis; magnetic resonance imaging (MRI) of the head and neck; and bilateral bone marrow aspiration or biopsy. 
Positron emission tomography (PET)-CT scans, bone marrow Epstein-Barr virus-encoded small RNA (EBER) staining, and Epstein-Barr virus (EBV) DNA blood levels were not included in the routine staging investigations in the study. Follow-up information was obtained from the patients' medical records or by telephone.

\section{Treatment}

The P-gemox regimen entailed intravenous injection of gemcitabine $\left(1250 \mathrm{mg} / \mathrm{m}^{2}\right)$ and oxaliplatin $\left(85 \mathrm{mg} / \mathrm{m}^{2}\right)$ and intramuscular injection of pegaspargase (2500 IU/ $\mathrm{m}^{2}$ ) on day 1 , repeated every 2 weeks. Alternatively, the regimen entailed intravenous injection of gemcitabine $\left(1000 \mathrm{mg} / \mathrm{m}^{2}\right)$ on days 1 and 8 and oxaliplatin $(130 \mathrm{mg} /$ $\mathrm{m}^{2}$ ) on day 1 with intramuscular injection of pegaspargase $\left(2500 \mathrm{IU} / \mathrm{m}^{2}\right)$ on day 1 , repeated every 3 weeks. The two regimens used similar dose intensities (i.e., the dose of effective drug administered per unit of time [in $\mathrm{mg}$ / $\mathrm{m}^{2}$ per week]). For patients who were in poor condition or experienced severe toxicity, we reduced the doses as follows. For patients who experienced severe hematologic toxicity, all the drugs were reduced $25 \%$ in the next course. For patients who experienced severe gastrointestinal disorder, oxaliplatin was reduced $25 \%$ in the next course. For patients who experienced severe liver dysfunction or coagulopathy, pegaspargase was reduced $25 \%$ in the next course.

During the chemotherapy intervals, patients with hematologic toxicity and a white blood cell count $<$ $2.0 \times 10^{9} / \mathrm{L}$ or absolute neutrophil count $\leq 1.0 \times 10^{9} / \mathrm{L}$ received granulocyte-colony-stimulating factor (G-CSF) $(5 \mu \mathrm{g} / \mathrm{kg} /$ day, hypodermically injected) until the neutrophil counts recovered. Patients with localized ENKTL were referred for primary involved-field radiation (IFRT) after receiving a maximum of 6-8 initial chemotherapy cycles. If patients with localized ENKTL only achieved stable disease (SD) following two cycles, they were administered primary IFRT. If patients had not achieved CR after four cycles, they were given IFRT. For patients with advancedstage or relapsed/refractory disease who had never been irradiated, IFRT of the primary anatomic site or residue lesion was administered after all chemotherapy treatments were complete. The IFRT median total dose was $56 \mathrm{~Gy}$, with a range of $40 \mathrm{~Gy}$ to $60 \mathrm{~Gy}$. In addition, patients could receive $\mathrm{HSCT}$ after achieving interim CR or PR. The decision was made at the discretion of the treating physicians, mainly on the basis of the patient's age and condition.

\section{Response and toxicity criteria}

Treatment responses were assessed every two chemotherapy cycles and classified as CR, PR, SD, or PD according to the Revised Response Criteria for Lymphoma
[35]. The overall response rate (ORR) was defined as the proportion of patients who achieved CR or PR. The interim response was assessed after two courses, and the completion response was defined as the response after the last course of P-gemox. After treatment was completed, patients were followed up and assessed by their oncologist in the outpatient department. Each assessment consisted of a physical examination, complete blood count, serum biochemistry (including LDH level), and either a CT scan, MRI of the involved region, or PET-CT scan. Toxicity after chemotherapy was evaluated according to the National Cancer Institute Common Terminology Criteria of Adverse Events v3.0.

\section{Statistical analysis}

OS was calculated from the date of the first administration of P-gemox to the date of death or last follow-up. Progression-free survival (PFS) was measured from the date of the first administration of P-gemox to the date of disease progression, relapse or death from any cause. The $\chi^{2}$ test was used to calculate statistical group comparisons of categorical variables. Survival analysis was performed using the Kaplan-Meier method, and curves were compared using the log-rank test. Univariate and multivariate analyses of independent factors for survival were performed using the Cox proportional hazard model. Two-tailed $P$ values of less than 0.05 were considered significant. Statistical analyses were performed by using SPSS 17.0 software.

\section{ACKNOWLEDGMENTS}

We thank the patients and their families and all the investigators, including the physicians, nurses, and laboratory technicians participating in this study. This work was supported by National Natural Science Foundation of China [contract/grant number: 30471976 and 81272620], Science and Technology Projects of Guangdong Province [contract/grant number: 2010B031600233 and 2010A090200019].

\section{CONFLICTS OF INTEREST}

The authors declare no conflicts of interest.

\section{REFERENCES}

1. Au WY, Weisenburger DD, Intragumtornchai T, Nakamura S, Kim WS, Sng I, Vose J, Armitage JO and Liang R. Clinical differences between nasal and extranasal natural killer/T-cell lymphoma: a study of 136 cases from the International Peripheral T-Cell Lymphoma Project. Blood. 2009; 113:3931-3937.

2. Li YX, Liu QF, Fang H, Qi SN, Wang H, Wang WH, Song 
YW, Lu J, Jin J, Wang SL, Liu YP, Lu N and Liu XF, et al. Variable clinical presentations of nasal and Waldeyer ring natural killer/T-cell lymphoma. Clin Cancer Res. 2009; 15:2905-2912.

3. Lee J, Suh C, Park YH, Ko YH, Bang SM, Lee JH, Lee DH, Huh J, Oh SY, Kwon HC, Kim HJ, Lee SI and Kim JH, et al. Extranodal natural killer T-cell lymphoma, nasal-type: a prognostic model from a retrospective multicenter study. J Clin Oncol. 2006; 24:612-618.

4. Siu LL, Chan JK and Kwong YL. Natural killer cell malignancies: clinicopathologic and molecular features. Histol Histopathol. 2002; 17:539-554.

5. Kim SJ and Kim WS. Treatment of localized extranodal NK/T cell lymphoma, nasal type. Int J Hematol. 2010; 92:690-696.

6. Cheung MM, Chan JK, Lau WH, Ngan RK and Foo WW. Early stage nasal NK/T-cell lymphoma: clinical outcome, prognostic factors, and the effect of treatment modality. Int J Radiat Oncol Biol Phys. 2002; 54:182-190.

7. Li YX, Yao B, Jin J, Wang WH, Liu YP, Song YW, Wang SL, Liu XF, Zhou LQ, He XH, Lu N and Yu ZH. Radiotherapy as primary treatment for stage IE and IIE nasal natural killer/T-cell lymphoma. J Clin Oncol. 2006; 24:181-189.

8. Wang ZY, Li YX, Wang WH, Jin J, Wang H, Song YW, Liu QF, Wang SL, Liu YP, Qi SN, Fang H, Liu XF and $\mathrm{Yu} \mathrm{ZH}$. Primary radiotherapy showed favorable outcome in treating extranodal nasal-type NK/T-cell lymphoma in children and adolescents. Blood. 2009; 114:4771-4776.

9. Kwong YL, Chan AC, Liang R, Chiang AK, Chim CS, Chan TK, Todd D and Ho FC. CD56+ NK lymphomas: clinicopathological features and prognosis. Br J Haematol. 1997; 97:821-829.

10. Kim WS, Song SY, Ahn YC, Ko YH, Baek CH, Kim DY, Yoon SS, Lee HG, Kang WK, Lee HJ, Park CH and Park K. CHOP followed by involved field radiation: is it optimal for localized nasal natural killer/T-cell lymphoma? Ann Oncol. 2001; 12:349-352.

11. Wang B, Lu JJ, Ma X, Guo Y, Lu H, Hong X and Li J. Combined chemotherapy and external beam radiation for stage IE and IIE natural killer T-cell lymphoma of nasal cavity. Leuk Lymphoma. 2007; 48:396-402.

12. Kwong YL. Natural killer-cell malignancies: diagnosis and treatment. Leukemia. 2005; 19(12):2186-2194.

13. Kim BS, Kim TY, Kim CW, Kim JY, Heo DS, Bang YJ and Kim NK. Therapeutic outcome of extranodal NK/T-cell lymphoma initially treated with chemotherapy--result of chemotherapy in NK/T-cell lymphoma. Acta Oncol. 2003; 42:779-783.

14. Drenou B, Lamy T, Amiot L, Fardel O, Caulet-Maugendre S, Sasportes M, Diebold J, Le Prise PY and Fauchet R. CD3- CD56+ non-Hodgkin's lymphomas with an aggressive behavior related to multidrug resistance. Blood. 1997; 89(8):2966-2974.
15. Yamaguchi M, Kita K, Miwa H, Nishii K, Oka K, Ohno T, Shirakawa S and Fukumoto M. Frequent expression of P-glycoprotein/MDR1 by nasal T-cell lymphoma cells. Cancer. 1995; 76:2351-2356.

16. Yamaguchi M, Kwong YL, Kim WS, Maeda Y, Hashimoto C, Suh C, Izutsu K, Ishida F, Isobe Y, Sueoka E, Suzumiya J, Kodama T and Kimura H, et al. Phase II study of SMILE chemotherapy for newly diagnosed stage IV, relapsed, or refractory extranodal natural killer (NK)/T-cell lymphoma, nasal type: the NK-Cell Tumor Study Group study. J Clin Oncol. 2011; 29:4410-4416.

17. Kwong YL, Kim WS, Lim ST, Kim SJ, Tang T, Tse E, Leung AY and Chim CS. SMILE for natural killer/T-cell lymphoma: analysis of safety and efficacy from the Asia Lymphoma Study Group. Blood. 2012; 120:2973-2980.

18. Jaccard A, Gachard N, Marin B, Rogez S, Audrain M, Suarez F, Tilly H, Morschhauser F, Thieblemont C, Ysebaert L, Devidas A, Petit B and de Leval L, et al. Efficacy of L-asparaginase with methotrexate and dexamethasone (AspaMetDex regimen) in patients with refractory or relapsing extranodal NK/T-cell lymphoma, a phase 2 study. Blood. 2011; 117:1834-1839.

19. Ando M, Sugimoto K, Kitoh T, Sasaki M, Mukai K, Ando J, Egashira M, Schuster SM and Oshimi K. Selective apoptosis of natural killer-cell tumours by 1-asparaginase. Br J Haematol. 2005; 130:860-868.

20. Escherich G, Zur SU, Zimmermann M and Horstmann MA. Clofarabine in combination with pegylated asparaginase in the frontline treatment of childhood acute lymphoblastic leukaemia: a feasibility report from the CoALL 08-09 trial. Br J Haematol. 2013; 163:240-247.

21. Lin N, Song Y, Zheng W, Tu M, Xie Y, Wang X, Ping L, Ying Z, Zhang C, Deng L, Liu W and Zhu J. A prospective phase II study of L-asparaginase- CHOP plus radiation in newly diagnosed extranodal NK/T-cell lymphoma, nasal type. J Hematol Oncol. 2013; 6:44.

22. Wang L, Wang Z, Chen X, Li Y, Wang K, Xia Y and Xia Z. First-line combination of gemcitabine, oxaliplatin, and L-asparaginase (GELOX) followed by involved-field radiation therapy for patients with stage IE/IIE extranodal natural killer/T-cell lymphoma. Cancer. 2013; 119:348-355.

23. Reyes VE, Al-Saleem $\mathrm{T}$, Robu VG and Smith MR. Extranodal NK/T-cell lymphoma nasal type: Efficacy of pegaspargase. Report of two patients from the United Sates and review of literature. Leukemia Res. 2010; 34:e50-e54.

24. Zinzani PL, Venturini F, Stefoni V, Fina M, Pellegrini C, Derenzini E, Gandolfi L, Broccoli A, Argnani L, Quirini F, Pileri S and Baccarani M. Gemcitabine as single agent in pretreated T-cell lymphoma patients: evaluation of the long-term outcome. Ann Oncol. 2010; 21:860-863.

25. Millikan RE, Plunkett WK, Smith TL, Williams DL and Logothetis CJ. Gemcitabine modulation of alkylator therapy: a phase I trial of escalating gemcitabine added to fixed doses of ifosfamide and doxorubicin. Cancer. 2001; 92:194-199. 
26. Kim KH, Joo YD, Sohn CH, Shin HJ, Chung JS, Cho GJ, Shin SH, Kim YS and Lee WS. Gemcitabine, etoposide, cisplatin, and dexamethasone in patients with refractory or relapsed non-Hodgkin's lymphoma. Korean J Intern Med. 2009; 24:37-42.

27. Ahn HK, Kim SJ, Hwang DW, Ko YH, Tang T, Lim ST and Kim WS. Gemcitabine alone and/or containing chemotherapy is efficient in refractory or relapsed NK/Tcell lymphoma. Invest New Drug. 2013; 31:469-472.

28. Oki Y, McLaughlin P, Pro B, Hagemeister FB, Bleyer A, Loyer E and Younes A. Phase II study of oxaliplatin in patients with recurrent or refractory non-Hodgkin lymphoma. Cancer. 2005; 104:781-787.

29. Faivre S, Raymond E, Woynarowski JM and Cvitkovic E. Supraadditive effect of 2',2'-difluorodeoxycytidine (gemcitabine) in combination with oxaliplatin in human cancer cell lines. Cancer Chemother Pharmacol. 1999; 44:117-123.

30. Lopez A, Gutierrez A, Palacios A, Blancas I, Navarrete M, Morey M, Perello A, Alarcon J, Martinez J and Rodriguez J. GEMOX-R regimen is a highly effective salvage regimen in patients with refractory/relapsing diffuse large-cell lymphoma: a phase II study. Eur J Haematol. 2008; 80:127132.

31. Dinndorf PA, Gootenberg J, Cohen MH, Keegan P and Pazdur R. FDA drug approval summary: pegaspargase (oncaspar) for the first-line treatment of children with acute lymphoblastic leukemia (ALL). Oncologist. 2007; 12:991998.
32. Li L, Zhang C, Zhang L, Li X, Wu JJ, Sun ZC, Fu XR, Wang XH, Chang Y, Wang R, Qiu YJ and Zhang MZ. Efficacy of a pegaspargase-based regimen in the treatment of newly-diagnosed extranodal natural killer/T-cell lymphoma. Neoplasma. 2014; 61:225-232.

33. Zhou Z, Li X, Chen C, Li X, Zhang L, Li L, Wang X, Ma W, Fu X, Wu J, Sun Z, Zhang X and Li Z, et al. Effectiveness of gemcitabine, pegaspargase, cisplatin, and dexamethasone (DDGP) combination chemotherapy in the treatment of relapsed/refractory extranodal NK/T cell lymphoma: a retrospective study of 17 patients. Aaa Hematol. 2014; 93:1889-1894.

34. Stock W, Douer D, DeAngelo DJ, Arellano M, Advani A, Damon L, Kovacsovics T, Litzow M, Rytting M, Borthakur $\mathrm{G}$ and Bleyer A. Prevention and management of asparaginase/pegasparaginase-associated toxicities in adults and older adolescents: recommendations of an expert panel. Leukemia Lymphoma. 2011; 52:2237-2253.

35. Cheson BD, Pfistner B, Juweid ME, Gascoyne RD, Specht L, Horning SJ, Coiffier B, Fisher RI, Hagenbeek A, Zucca E, Rosen ST, Stroobants S and Lister TA, et al. Revised response criteria for malignant lymphoma. J Clin Oncol. $2007 ; 25: 579-586$. 